\title{
INFLUENCE OF INSTRUCTION ON STUDENTS' PERFORMANCE IN BIOLOGICAL DRAWING IN SOKOTO STATE, NIGERIA
}

\author{
REBECCA UGBONJI IBRAHIM
}

\begin{abstract}
This study investigated the influence of instruction on the drawing performance of students in Sokoto State, Nigeria. The main objective was to find out whether students will improve in drawing performance if they are tutored on the salient features of biological drawing. A pretest-posttest-quasi experimental design was used in carrying out the research. The population of the study was the Senior Secondary 1 students of Sokoto State. The estimated number of this group of students according to Ministry of Education Sokoto was 18,932. Purposive sampling technique was used to select six schools that participated in the study. The treatment involved 16 sessions of teaching focusing on various aspects of biological drawing and labelling. Biology Drawing Test (BDT) was administered on the subjects to test the students' acquired knowledge and application of the knowledge in practical drawing and labelling tasks. The measures obtained from the instrument were subjected to statistical analyses of t-test to test the two hypotheses of the research. The findings showed that the experimental groups performed significantly better than the control group in both drawing and labeling skills. The research, anong others, recommended that biology teachers should provide specific instructions on drawing and labelling to students for effective learning and understanding of biological concepts.
\end{abstract}

\section{Introduction}

Biology is one of the science subjects offered by most of the senior secondary school students as a required subject in most science based careers. This role served by the subject is unfortunately threatened by poor performance of students in both internal and external examination in biology (Balogun 1994). This threat therefore necessitates the need for researches on teaching methodology that could improve the performance of students in this area of science.

Davis (1997) suggests the teaching of drawing and labelling in biology as an important way of enhancing students achievement in the subject. Experienced biology teachers, particularly at secondary school level, will probably confirm that it is hardly practicable, if not impossible, to make a meaningful teaching, learning and understanding of virtually all biology concepts without drawing some diagrams to illustrate them. This is simply because diagram is the major vehicle which drives the teaching of content and process skills in biology (Finely, 1998). Peak (1996) sees drawing as an important aspect of biology and therefore argues that students need to be taught basic drawing skills for them to understand the content of most biological concepts, thus, leading to better achievement in the subject. It is on this background that the current study on the effect of teaching drawing and labelling tips in biology on the performance of secondary school students in Sokoto State was addressed.

\section{Statement of Problem}

There is a general observation that students at all levels in biology classes exhibit fear for drawing and labeling. As a result, they tend to develop a negative attitude towards

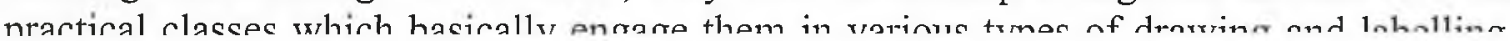


Most students believe that they do not know how to draw hence every question involving drawing is either poorly attempted or totally ignored thereby leading to poor performance in the subject that is recorded every year in WAEC and NECO. This research effort attempts to expose students to drawing and labelling skills as a means of reducing to a minimum level the problem of poor performance of students in biological drawing.

\section{Research Questions}

The following research questions were addressed in this study:

a. Does competence in biological drawing affect the performance of Senior Secondary School students in biology?

b. Does competence in labelling affect the performance of Senior Secondary School students in biology?

\section{Null Hypotheses}

The following null hypotheses were tested in the course of this study:

a. There is no significant difference between the performance of the experimental and control group in biological drawing.

b. There is no significant difference between the performance of the experimental and control group in labelling ability.

\section{Review of Related Literature}

\section{Meaning of Drawing and Labelling}

Scholars have offered their opinion on the meaning of drawing. Holm (2006) sees drawing as a form of language used in describing one's observation about an object. Nwagbo (2006) considers drawing as the highest form of human expression. According to Uzuoagba (2000), drawing assists man to extend his power of visual imagery and his ability to sort and find meaning in what he sees. From the above definitions we can simply regard drawing as a useful tool in virtually all science subjects.

\section{Importance of Drawing in Science}

Bajah (1998) defines science as a discovering process that reveals relationship existing in nature. Science as defined by Abdullahi (1982) is the activities culminating into testable, falsifiable and verifiably body of knowledge. It comprises knowledge about nature and that form of human activity which involves the contemplation and analysis of natural phenomena. Biology as one of the basic science subjects deals with nature, which include plants and animals. This aspect of nature needs careful observation for one to be able to make meaningful study of them and this is what drawing is all about.

Several writers and science educators such as Hirschorn (1992), Anderson, John, Bruwell, and Shell (1998) have expressed their opinion on the importance of drawing in science education. For instance, Hirschorn (1992) viewed science as a dynamic, ever-changing process of seeking new knowledge and a way of explaining events and phenomena in 
Most students believe that they do not know how to draw hence every question involving drawing is either poorly attempted or totally ignored thereby leading to poor performance in the subject that is recorded every year in WAEC and NECO. This research effort attempts to expose students to drawing and labelling skills as a means of reducing to a minimum level the problem of poor performance of students in biological drawing.

\section{Research Questions}

The following research questions were addressed in this study:

a. Does competence in biological drawing affect the performance of Senior Secondary School students in biology?

b. Does competence in labelling affect the performance of Senior Secondary School students in biology?

\section{Null Hypotheses}

The following null hypotheses were tested in the course of this study:

a. There is no significant difference between the performance of the experimental and control group in biological drawing.

b. There is no significant difference between the performance of the experimental and control group in labelling ability.

\section{Review of Related Literature}

\section{Meaning of Drawing and Labelling}

Scholars have offered their opinion on the meaning of drawing. Holm (2006) sees drawing as a form of language used in describing one's observation about an object. Nwagbo (2006) considers drawing as the highest form of human expression. According to Uzuoagba (2000), drawing assists man to extend his power of visual imagery and his ability to sort and find meaning in what he sees. From the above definitions we can simply regard drawing as a useful tool in virtually all science subjects.

\section{Importance of Drawing in Science}

Bajah (1998) defines science as a discovering process that reveals relationship existing in nature. Science as defined by Abdullahi (1982) is the activities culminating into testable, falsifiable and verifiably body of knowledge. It comprises knowledge about nature and that form of human activity which involves the contemplation and analysis of natural phenomena. Biology as one of the basic science subjects deals with nature, which include plants and animals. This aspect of nature needs careful observation for one to be able to make meaningful study of them and this is what drawing is all about.

Several writers and science educators such as Hirschom (1992), Anderson, John, Bruwell, and Shell (1998) have expressed their opinion on the importance of drawing in science education. For instance, Hirschorn (1992) viewed science as a dynamic, ever-changing process of seeking new knowledge and a way of explaining events and phenomena in 
nature. Micheal (1997), Kuo (1998) and Uzoagba (2000) all share the opinion that a strong relationship exists between the hands, brain and the heart in a highly coordinated fashion to do useful tasks in the area of science. Okebukola (1998) states that there are positive correlations between higher performance in biology and the drawing ability of the students. Anderson, John, Bruwell, and Shell (1998) stress that the place of drawing in virtually all science subjects and science-oriented courses cannot be over emphasized. For example the science of medicine, genetic engineering, biotechnology and pollution control management are all areas that play vital role in the life of man and to make a meaningful study of these courses, drawing background is required hence the need to inculcate its skills into students right from elementary school.

\section{Drawing in Biology}

Drawing is an important aspect of biology and every biology student needs a bit of drawing skill if he is to perform well in the subject. The students' knowledge of biology is assessed from three perspectives; the practical, objective and the theory parts and all these aspects involve drawing in one way or the other. Balogun (1994) and Akinmade (1999) attribute the poor performance of students in biology to their inability to tackle biology practical questions which are heavily loaded with drawing activities. A number of authors have also confirmed that secondary school students commit a number of errors in practical biology examination and this affect their performance in the practical examination as well as in the subject as a whole (Nworgu (1999). Against this background, there is the need to update the knowledge of students about what examiners look out for in biology practical examination and questions that require drawing specifically.

Adams (1988) in his research work proves that error analysis in biology practical is a useful tool for detecting deficiency in terms of practical skills such as drawing as well as tackling the problems. Brent (2004), Johnson (1990) and Nworgu (1999) identified eight major areas of difficulties or errors encountered by biology students during practical lessons. Out of these eight major errors, five were from drawing and labeling which include:

1. Title of diagram drawn: This ranges from no name or no view of the specimen.

2. Drawing line: Students are found to use wooly or broken lines, use double line or broad single line to represent parts within the diagram.

3. Accuracy of drawings or details: Many students lack the ability to represent special features of specimens drawn.

4. Inability to label parts observed or drawn: Several students are found using double line as guide line to label a single part while others were found using lines that cross one another as guide lines to different parts of the specimen. Many others use lines that do not touch the part they labelled.

5. Magnification: Many students cannot state the exact magnification of the drawing made and many others do not state it at all.

\section{Teaching Drawing Skills}

As a biologist, drawing is very important to get one's ideas on the paper as quickly as possible thus it is considered to be a vital skill to master. From classroom experience, many students believe that the ability to draw is in-born. Therefore, they wonder whether 
drawing can really be taught. Marjorie and Brent (2006) strongly believe that children can really be taught how to draw and that the responsibility of teaching children drawing lies with both parents and teachers. In teaching drawing skills, teachers should expect different reactions from different children, particularly in their level of understanding and performance (Nick 1999). Observational skill is an important competence that is required by students at secondary school level for proper competence in drawing. The teacher should therefore give adequate attention to the development of this skill in the pupils. This is because accurate observation is required for one to be able to sketch an object in any type of drawing in biology.

\section{Developing Observational skills in students}

Ability to observe is a skill required in the study of science and in biological drawing in particular hence the need for proper development of this skill in our biology students if they are to perform to expectation in questions requiring drawing (Cirfat, Zumyil, \& Ndetshak 2007). Observation skill can be developed or promoted in students by helping them to be conversant with the use of some laboratory instruments such as microscope, hand lens and the eyes as suggested by Adams (1988).

Akinmade (1999) contends that teaching the students techniques of viewing specimens on slides using microscope will enable them observe and accurately represent or draw the specimen on paper. It will also assist the students in proper estimation of magnification of the specimen, as it is required in most external examination such as WASSCE.

Having acquired observational skill, which is the basic element needed for accurate drawing exercise, the students can be introduced to other drawing skills such as manipulation of hands for proper drawing. Sketching of object requires manipulation of the arm, which depends on the type of drawing. Mia (1990) identifies four types of drawing in biology. These include: Drawing from the real object, drawing from the chalkboard, drawing from the textbook and drawing from slides under microscope. Basically, all these drawings involve the use of shoulder and wrist to sketch either on the paper or chalkboard. Once a student learns to master the movement of the arm from the shoulder, he or she can confidently sketch a clean large drawing. Proper measurement also counts as part of the quality of the diagram.

\section{Research Design}

This study was conducted using a pre-test post-test quasi experimental design. The target population for the study was the Senior Secondary School I (SS I) students in Sokoto State. Purposive sampling technique was used to select six senior secondary schools that participated in the study on the principle of intact class. Four schools served as experimental groups while two served as control. A total of 300 subjects participated in the study.

\section{Instrumentation}

A treatment involving classroom teaching was given to the experimental groups aimed at conveying information about biological drawing and labelling skills. The teaching session involved sixteen lessons per school focusing on various aspects of biological drawing and labelling. Various drawings such as drawing under microscope, chalkboard drawing and 
drawing from real objects etc were taught to the experimental group. The teaching session lasted for eight weeks of two lessons per week. Biology Drawing Test (BDT) was administered on the subjects to test the students' acquired knowledge and application of the knowledge in practical drawing and labelling tasks. The Instrument was validated by experts in education and biology education. The reliability of the instrument was established using test-retest method and a reliability coefficient of 0.88 was obtained.

\section{Data Analysis}

The measures obtained from the instrument were subjected to statistical analyses to test the hypotheses of the research. Frequency tables were used to present the data collected. The mean, standard deviation and t-test were used to test the two null hypotheses of the research.

\section{Hypothesis I: There is no significant difference in the performance of experimental and control groups in biological drawing.}

The t-test statistic was used to test the differences observed in the mean scores of experimental and control group on the post-test. The results are presented in Table I.

Table I: Result of T-Test of Experimental Vs Control Groups in Drawing

\begin{tabular}{lllllll}
\hline Variables & $\begin{array}{l}\text { No. of } \\
\text { Cases }\end{array}$ & Mean & SD & $\begin{array}{l}\text { t- } \\
\text { calculated }\end{array}$ & Table-t & df \\
\hline Experimental Group & 206 & 21.31 & 4.61 & 19.01 & 1.97 & 298 \\
Control Group & 94 & 11.64 & 3.83 & & & \\
\hline
\end{tabular}

Table I presents the statistical analysis of the experimental and control groups' results on drawing. The table shows that the Experimental Group obtains a mean score of 21.31 and a standard deviation of 4.61 while the Control Group has a mean score of 11.64 and a standard deviation of 3.84. The calculated t-value is 19.01 and the table-t is 1.97 at 298 degree of freedom. From the Table I, it could be seen that the calculated value of $t$ is greater than the table value at alpha level of 0.05 . Therefore, the hypothesis is rejected. This therefore means that the experimental group performed significantly better than the control group in the biology drawing test as a result of the treatment they were exposed to.

Table II: Result of T-Test of Experimental -Control Groups in Labelling

\begin{tabular}{lllllll}
\hline Variables & $\begin{array}{l}\text { No. of } \\
\text { Cases }\end{array}$ & Mean & SD & t-calculated & Table-t & df \\
\hline Experimental Group & 206 & 11.83 & 3.8 & 16.19 & 1.97 & 298 \\
Control Group & 94 & 5.77 & 2.55 & & & \\
\hline
\end{tabular}

Table II presents the result of the experimental and control groups in labelling. The table shows that the experimental group recorded a mean score of 11.83 and a standard deviation of 3.8 while the control group has a mean score of 5.77 and standard deviation of 2.55 . The calculated t-value is 16.19 while the table-value is 1.97 at 298 degree of freedom. This indicates that experimental group performed significantly better than the control group in the labelling component of the research. On the strength of the results in the table I and II above, the two null hypotheses are therefore rejected. 
Influence of Instruction on Students' Performance in Biological Drawing in Sokoto State, Nigeria

\section{Summary of Findings}

Following the analyses presented above, these findings have emerged from the research:

1 The experimental groups performed significantly better than the control groups in the learning of drawing skills as a result of the treatment they were exposed.

2 The experimental groups also performed significantly better than the control groups in the labelling component of the research.

\section{Discussion of findings}

From the analysis of the data obtained, it is evident that significant differences exist in students drawing ability between experimental and control groups. The experimental groups that were taught drawing and labelling skills were found to have performed better than their control groups counterparts in biological drawing tests. This finding is in accord with the findings of Michael (1997), Kuo (1998) and Uzoagba (2000) who gave evidence that effective achievement can be obtained in the learning of biology if concepts are taught along with drawing and labelling skills.

The findings also agreed with that of Onikola (1998) who states that there are positive correlations between higher performance in biology and the drawing ability of the students. The superior performance of the experimental groups who were taught tips on drawing and labelling over the control groups who were not exposed to the treatment is a testimony to that.

Adams (1988) established that the success of a child in learning process is the frame work of relevant concepts the individual possesses. Hence, the knowledge of drawing and labelling presented to the students in this study played a very important role in the drawing and labelling abilities of the experimental group which will appreciably promote acquisition of biological concept. Evidently, the better performance of the experimental group over their control group counterparts were as a result of knowledge of drawing and labelling skills.

\section{Conclusion}

From the findings above, the following conclusions could be made about drawing and labelling abilities of secondary school biology students in Sokoto State. Generally there was significant difference in performance of those who were taught basic drawing and labelling skills and the control group who were not taught. These differences were found in their score on the BDT. This shows that majority of the secondary school students in Sokoto State irrespective of types of school attended (private or public) and gender can perform better in terms of achievement in biology so long as they are exposed to the right knowledge and skills. It also suggests that drawing and labelling skills are of great importance to all biology students if meaningful achievement is to be recorded.

\section{Recommendations}

In view of the current findings, the following recommendations are proposed:

1. From the interaction of the researcher with the students of the schools visited, it was observed that most biology concepts are taught through expository method. 
Since the results of this research indicate the effectiveness of drawing and labelling in enhancing student's performance in biology, biology teachers are advised to adopt and sustain the use of drawing and labelling in teaching most biological concepts for effective learning and understanding of those concepts.

2. Biology teachers should teach drawing skill along with content so that students will feel comfortable when answering biology questions and thus perform well.

3. Special training and retraining should be organised for biology teachers on the importance of drawing and labelling skills in biology and how to develop these skills in students for better performance in the subject.

4. Teachers should provide students with opportunities to practice drawing and labelling both at school and home as part of their various biology take-home assignments. This will provide students with opportunities to develop the drawing and labelling skills through consistent practice.

5. School authorities should introduce practical classes in biology as from SSI to develop and facilitate students' interest in practical generally and biological drawing in particular.

6. Adequate supervision should be provided to ensure that teachers of biology conduct practical classes. 


\section{Reference}

Abdullahi, A. (1982). Science Teaching in Nigeria, Ilorin: Atato Press.

Adams, B. (1988). "The relationship of Intelligence to ability in Arts". Journal of Educational Research. 3: 38-42.

Akinmade, C. T. O. (1999). The process approach to science teaching. A keynote address presented at Science Teachers Association of Nigeria Biology Panel National workshop held at Government College Katsina.

Anderson, A. John, K.O, Bruwell, M. and Shell, F. (1998). Developing children's thinking through drawing. Prentice Hull. Journal of research in science teaching, 2 (14): $27-32$.

Bajah, S.T (1998). Stepping into Science: the ELSSA way. Science Teachers Association Bulletin, 15 (2).

Balogun, T. A. (1994). Gender Issues in the Teaching of Science, Technology and Mathematics, Perspectives on women in science and technology in Nigeria: Sam Bookman education and communication services.

Bartel, J. P (2007). Guide for Biological Drawing. Retrieved from

Brent, W. (2004). "What skills are Needed to Teach Integrated Science and How can their Development be Monitored?". New Trends in Integrated Science Teaching, IV. Paris. UNESCO Press.

Bybee, R. W. (1998). Improving precollege science education - the involvement of scientists of engineers. Enlisting the support of scientists and engineers to translate science education standards into effective science programs. Journal of College Science Teaching, 27: 324-328.

Cirfat, A. B. Zumyil, C. F. and Ndetshak T. M. (2007). Selected Basic laboratory skills expected of biology teacher. Science Teachers Association National Biology Workshop. St. John's College Jos Plateau State.

Congan, P.V (1979). "Science Education for Society" in Reay, Journal (Ed). New Trends in Integrated science Teaching, Paris: UNESCO Press, 5: 153-159.

Davis, D. I. (1997). Teaching Methodologies in Art: An Experiment in Depth and Breath Approaches to Instruction. The Texas Tech. Press.

Day, M. D. (1996). The compatibility of art history and studio art activity in the junior high school art program. Studies in Art Education, 10 (2): 57-65.

Finely, F. N. (1998). Science Processes, Journal of Research in Science Teaching, 1 (20): 47-54. 
Hirschorn, J. (1992). Engineering and non-engineering students' attitudes towards science and technology. Science Education, 58 (2): 331-359.

Holm, C. (2006). Curriculum Plan for teachers and Home Schoolers. Retrieved from Teaching Drawing Skills Rttp:/www.everyday.com/draw.html on 28/02/2007

Johnson, T. I. (1990). Craft, Design and Technology". Physics Education, 21 (6): 223229.

Kuo, Y. Y. (1998). A comparative study of creative thinking between delinquent boys and non-delinquent boys. Unpublished doctoral dissertation, ABU Zaria.

Marjorie, B. \& Brent, W. (2006). Teach Children to Draw. Pentice Hall. Retrieved from

Mia, J. (1990). Teach Your Child to Draw. Lowell House.

Micheal, J. A. (1997). A Handbook for Instructors and Students Based upon Concepts and Behaviors. New York: Vantage Press.

Nick, N. (1999). Purpose of Art. Retrieved from http://artrenewal.com/articles/2003/Best of ARC/bestl.asp?.msg $=52 \&$ forumID $=12$ on $17 / 04 / 2007$

Nworgu, S. T. (1999). The effects of single sec and co-education on science subject preference and choice. School science Review, 62 (21): 520-531.

Okebukola, P. A. Apkan, E. U. Ahove, M. Kola-Olusanya A. N. \& Ogunsola, B. (1997). Highlights of Strategies for Environmental Education, Science Teachers Association of Nigeria, Environmental Education Series, 1: 136-45.

Onikola, P. A. (1998). Highlights of Strategies for Greater Achievement in Science Education, Science Teachers Association of Nigeria, Environmental Education Series, 2: $123-45$.

Peak, L. (1996). Pursuing Excellence: A Study of U.S Eighth Grade Mathematics and Science Teaching, Learning, Curriculum and Achievement in International Context. Washinton, DC. United States Department of Education. OERI.

Uzoagba, I. N. (2000). Understanding Art in General Education. Africana-fep publisher Limited.

Wushishi, D. I. (2001). The Effects of Concept Mapping and Analogy on Secondary School Students Achievement in Chemistry. Unpublished Master Thesis, UDUS Sokoto. 